\title{
Loss of electrically active myocardium during anterior infarction in $\operatorname{man}^{1}$
}

\author{
ANDREW P. SELWYN, E. OGUNRO, AND J. P. SHILLINGFORD \\ From the Cardiovascular Research Unit, Royal Postgraduate Medical School, Hammersmith Hospital, \\ London
}

$A$ method has been developed of praecordial mapping of changes in $R / S$ ratio and the appearance of $Q$ waves in acute myocardial infarction. Observation of the serial changes in $R$ and $Q$ waves in 40 patients with uncomplicated anterior infarction shows that the loss of electrically active myocardium occurs within 6 hours of the onset of chest pain. Complications, such as recurrent chest pain, associated with extension of myocardial necrosis can be identified and assessed. The total praecordial changes in $R / S$ ratio and $Q$ wave amplitude correlate with the total MB fraction of creatine kinase activity released into the plasma in 20 patients after uncomplicated anterior infarction. This technique for identifying those factors that may modify the progressive loss of active myocardium in the early phase of acute infarction of the heart is noninvasive and repeatable.

In patients with acute myocardial infarction the extent of tissue damage is important in relation to morbidity and mortality. Recently research has been directed to the development of techniques and interventions that will lead to the salvage of active myocardium in acute infarction (Maroko et al., 1971; Maroko, 1974).

The electrocardiogram undergoes a series of changes after the onset of acute regional myocardial ischaemia (Johnston et al., 1935; Wilson et al., 1935a, b). The localised loss of $R$ waves and the appearance of $Q$ waves is thought to represent the loss of electrically active myocardium (Johnston et al., 1935; Wilson et al., 1935a; Prinzmetal et al., 1954; Shaw et al., 1954; Selwyn and Shillingford, 1977). Praecordial surface mapping of the electrocardiogram in man has been developed to follow the changes in $R / S$ ratio, and amplitude of $R$ and $Q$ waves during acute myocardial infarction (Selwyn and Shillingford, 1977).

It is the purpose of this paper to describe the pattern and time course of the loss of electrically active myocardium in a group of patients with uncomplicated anterior infarction. A relation is shown between these changes in the praecordial map and the extent of cell necrosis assessed by the total release of the myocardial fraction of creatine kinase (MB CK). The significance of the loss of $R$ waves and the appearance of $Q$ waves in relation to the underlying pathology and the possibility of limiting infarct size by therapeutic intervention is discussed.

${ }^{1}$ This work was financed in part by the British Heart Foundation. Received for publication 28 January 1977

\section{Patients and methods}

The 45 patients (34 men and 11 women, aged between 42 and 74 years, mean 55 years) were admitted to the coronary care unit at the Hammersmith Hospital with a clinical diagnosis of acute anterior myocardial infarction. All these patients developed electrocardiographic evidence of acute myocardial infarction on the standard 12-lead electrocardiogram and all had a diagnostic rise in serum enzymes. While in the coronary care unit, 40 of the patients did not develop any of the following major complications: (a) recurrent chest pain lasting more than 10 minutes after the initial episode of pain; (b) clinical or chest $x$-ray evidence of congestive heart failure or pulmonary oedema; or (c) cardiac rhythm disturbances other than isolated unifocal ventricular ectopic beats. Five of the 45 patients had a number of complications after admission to the coronary care unit. These were: (a) recurrent chest pain 4 to 12 hours after the onset of the first episode in 3 patients; and (b) ventricular fibrillation followed by recovery in 2 .

Praecordial electrocardiographic maps were recorded on admission, again at 1 hour, then 4hourly for 12 hours, and daily thereafter. Additional readings were made if the clinical condition changed. Recordings were made using a direct writing ink jet electrocardiograph (Elema-Schonander Mingograph) on 3 channels simultaneously. The gain employed was $10 \mathrm{~mm}$ for $1 \mathrm{mV}$ and the paper speed was $25 \mathrm{~mm}$ per second. Welsh suction type electrodes with a contact diameter of $1 \mathrm{~cm}$ were used. Electrocardiograms were recorded from 1186 
72 points distributed evenly over the praecordium as described by Reid et al. (1971).

The amplitude of the $R$ and $S$ waves was measured in millimetres to the nearest $0.5 \mathrm{~mm}$ using the TP segment as the isoelectric line, or the PQ segment when there was no isoelectric TP segment as a result of tachycardia. The $R / S$ ratio was calculated at each of the 72 positions. The $R$ wave amplitude in millimetres was used in place of $R / S$ ratio from those sites where the $S$ wave measured less than $0.5 \mathrm{~mm}$. Maps were always recorded with the patients at rest at $45^{\circ}$. The $R / S$ ratios were recorded on a standard diagram in which the 72 points were shown at $1 \mathrm{~cm}$ intervals (Selwyn and Shillingford, 1977). The appearance of QRS widening, bundle-branch block, or pathological axis changes can alter the $R / S$ ratio and $R$ wave amplitude. Patients whose electrocardiograms showed QRS widening beyond $110 \mathrm{~ms}$ or pathological axis changes beyond $30^{\circ}$ to $130^{\circ}$ in the frontal plane were therefore excluded from this study. Pathological $Q$ waves were identified using Minnesota code criteria (Blackburn et al., 1960; Rose and Blackburn, 1968).

Praecordial maps were recorded from 10 men and 10 women who had no evidence of cardiovascular disease on history, physical examination, chest $x$-ray film, or electrocardiogram. The age of the subjects in this control group was evenly distributed between 20 and 70 years. The mean, 68 per cent, and 95 per cent confidence limits (log normal distribution) of the $20 \mathrm{R} / \mathrm{S}$ ratios at each of the 72 positions of the praecordial electrocardiogram were calculated. The 72 mean $R / S$ ratios obtained from the normal group were used to calculate a single mean and standard error for the $R / S$ ratio of the whole praecordial map. The reproducibility of praecordial mapping has already been reported (Selwyn and Shillingford, 1977; Selwyn et al., 1977). The surface maps produced in this way from patients suffering acute infarction show areas of $Q$ waves, $Q R$ or $Q r$ waves, $R / S$ ratios with loss of $R$ wave up to and beyond the 95 per cent confidence limit of the normal group, $R / S$ ratios with loss of $R$ wave up to and beyond the 68 per cent confidence limit of the normal group.

The serial measurements of mean praecordial $R / S$ ratio (as shown in Fig. 3 and $4 A$ were used to display the time course for the regional praecordial loss of $R$ waves in the patients suffering acute infarction. This does not include the development of $Q$ waves.

Five $\mathrm{ml}$ of venous blood samples (taken at 3 hours intervals for the first 24 hours after the onset of chest pain, then 6 hourly for 4 days) were drawn from 20 of the 40 patients with uncomplicated infarction and from the 5 patients with complications. These samples were placed in lithium heparin tubes and centrifuged at $2000 \mathrm{~g}$ for 10 minutes. Total plasma CK activity was measured spectrophotometrically (Cecil 272 system spectrophotometer, Cecil Instruments, Cambridge) by the method of Oliver (1955) as modified by Hearse $e t$ al. (1973). Using this method the upper limit of plasma CK for healthy subjects is $50 \mathrm{mU} / \mathrm{ml}$ (Ogunro et al., 1977).

Samples with activity $250 \mathrm{mU} / \mathrm{ml}$ or more were diluted before determination of total CK. In order to minimise the dilution-activation effect observed with plasma $\mathrm{CK}$, heat inactivated plasma was used as diluent (Craig et al., 1967). Isoenzymes were separated by electrophoresis on agarose gels and quantified in aqueous solution by fluorimetry (Ogunro et al., 1977). This measurement is sensitive, specific, and linear (Ogunro et al., 1977). MB CK isoenzyme release curves were constructed by measuring the plasma $\mathrm{MB} \mathrm{CK}$ activity $(\mathrm{mU} / \mathrm{ml})$ at stated time intervals after the onset of chest pain. The area under each curve was used as an index of the total activity of $\mathrm{MBCK}$ released into the plasma.

In order to test the significance of changes in $R / S$ ratio, and of amplitude of $R$ and $Q$ waves, an analysis of variance was used. The variables included in this test were time, posture, respiration, and replacing electrodes. A two-tail test of significance was used to assess the difference between the complicated and uncomplicated groups.

\section{Results}

Previous studies of the reproducibility of praecordial mapping have shown that variables such as change in posture and phase of respiration have a significant effect and must be taken into account when assessing electrocardiographic changes caused by cardiac events (Selwyn and Shillingford, 1977; Selwyn et al., 1977). The distribution of praecordial $R / S$ ratios for the 20 normal individuals with no cardiovascular disease was log normal, and is shown for the 9 positions of row $D$ of the praecordial map in Fig. 1A. Similar figures were constructed for the remaining horizontal rows of the surface map (Selwyn and Shillingford, 1977). The mean value of the $R / S$ ratio at each of the 72 positions of the praecordial map in the control group was used to calculate a single mean $R / S$ ratio $\pm S E M$ for the whole praecordial map. In the normal group this was $4 \cdot 2 \pm 0 \cdot 46$.

UNCOMPLICATED GROUP

Fig. 1B shows the serial changes in $R / S$ ratio, and 


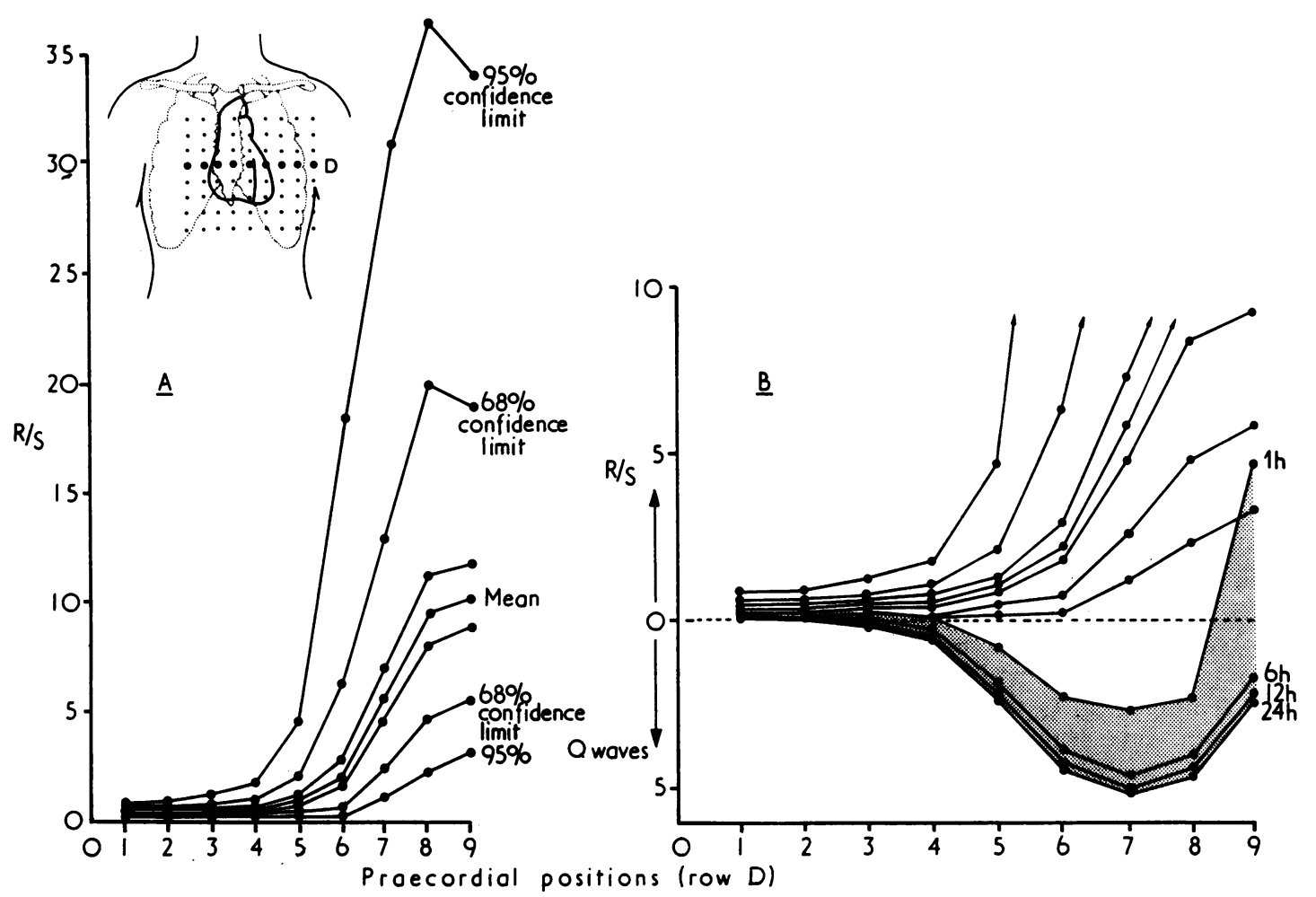

Fig. 1 (A) The praecordial $R / S$ ratios from the 9 positions of horizontal row $D$ in 20 individuals with no evidence of cardiovascular disease. (B) The praecordial $R / S$ ratios from the 9 positions of row $D$ showing the normal range and the changing pattern in 4 praecordial maps taken from a patient with anterior infarction. Positive values show $R / S$ ratios and negative values show the pathological $Q$ waves.

$\mathrm{Q}$ wave amplitude at the 9 positions of row $\mathrm{D}$ in 4 praecordial maps from a patient with uncomplicated anterior infarction. Fig. 2 shows the serial changes in the praecordial maps in a patient with uncomplicated anterior myocardial infarction. Fig. 3 shows the mean $R / S$ ratio $\pm S E M$ for all the praecordial maps in the control group: these show a \pm 4 per cent variation when these individuals are mapped over 4 days (Selwyn and Shillingford, 1977). Fig. 3 also shows the mean R/S ratio \pm SEM calculated from the group of patients with uncomplicated anterior myocardial infarction. The number of patients available for study in each time interval after the onset of chest pain is indicated. The $R / S$ ratio in 3 of the 6 patients mapped in the first hour from the onset of chest pain showed an increase from $3 \cdot 7 \pm 0 \cdot 1$ to $4 \cdot 4 \pm 0 \cdot 2$. These 3 patients were studied within 20 minutes from the onset of chest pain. The $R / S$ ratio then showed a rapid decrease from $3.5 \pm 0.3$ to $1.85 \pm 0.7 \mathrm{~mm}$ between the first and sixth hour after the onset of chest pain. After 12 hours changes in $R / S$ ratio were small, difficult to detect, and approached the \pm 4 per cent variation of the technique. $Q$ waves appeared in the praecordial maps at $112 \pm 5 \cdot 3$ minutes.

Fig. 4A shows these serial changes in $R / S$ ratio in the uncomplicated group and also the serial changes in a patient with anterior infarction who had a second episode of chest pain 12 hours after the onset of the initial pain. The changes seen in mean praecordial $R / S$ ratio in the uncomplicated group were significantly different from those in the 5 individuals who had complications $(M D=1 \cdot 10$, $\mathrm{T}=18.9, \mathrm{P}=<0.001$ ). Fig. $4 \mathrm{~B}$ shows the pattern and time course of plasma MB CK activity in 20 of the 40 patients with uncomplicated anterior infarction. This is also shown for the same patient with recurrent chest pain, and differed significantly from that of the uncomplicated group, suggesting a second episode of necrosis.

Fig. 5 shows the serial praecordial surface maps in this patient and shows the extension of the area of $Q$ waves, $Q r$ waves, and $R / S$ ratio loss. 

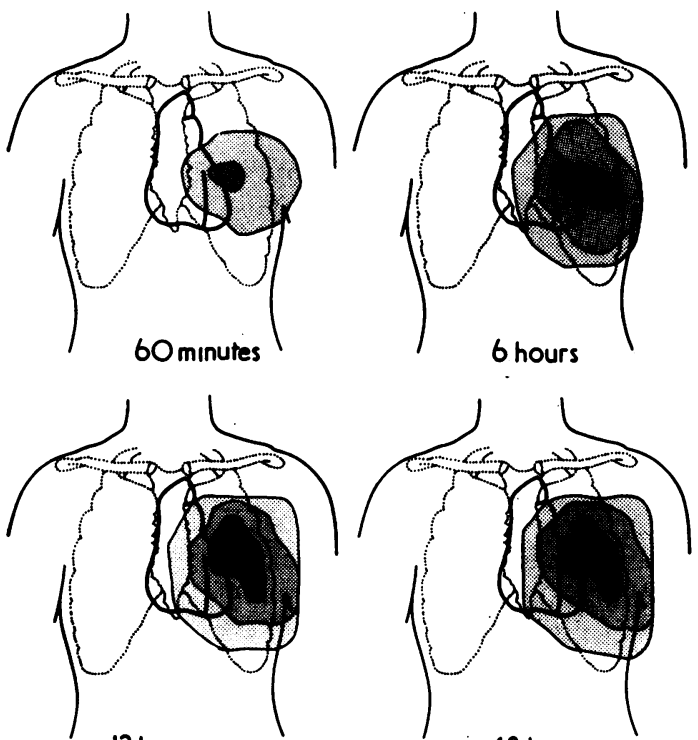

12 hours
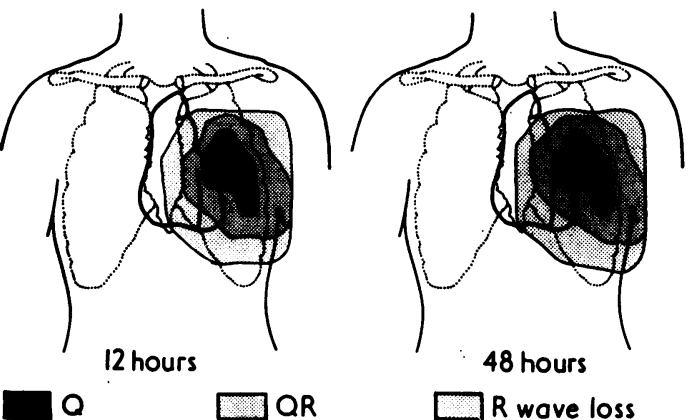

48 hours

$R$ wave loss

Fig. 2 Serial praecordial surface maps from a patient with uncomplicated anterior infarction. The rapid loss of $R$ waves and appearance of $Q$ waves occur within 6 hours from the onset of chest pain. $R$ wave loss implies decrease in $R / S$ outside 95 per cent confidence limits (or $r<0.5$ ).
Fig. 6 shows a relation between the total MB CK activity released and the mean $R / S$ ratio at 24 hours in patients with anterior infarction $(P=<0.001$, $\mathrm{R}=-0 \cdot 89, \mathrm{~N}=20$ ).

\section{Discussion}

Wilson et al. (1935a) showed that loss of $\mathrm{R}$ wave amplitude occurred in the epicardial leads over

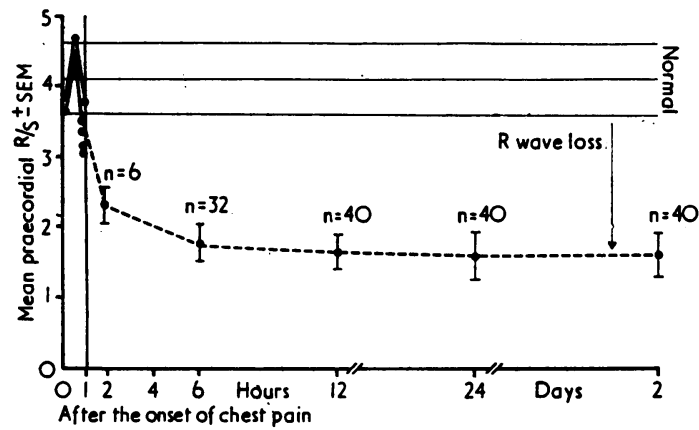

Fig. 3 Mean $\pm S E M$ praecordial $R / S$ ratio in 40 patients with uncomplicated anterior infarction is shown at specified times after the onset of chest pain. The number of patients ( $n$ ) available for study at each time is shown above. Mean $\pm S E M$ of the praecordial $R / S$ ratio in the normal group is also shown.
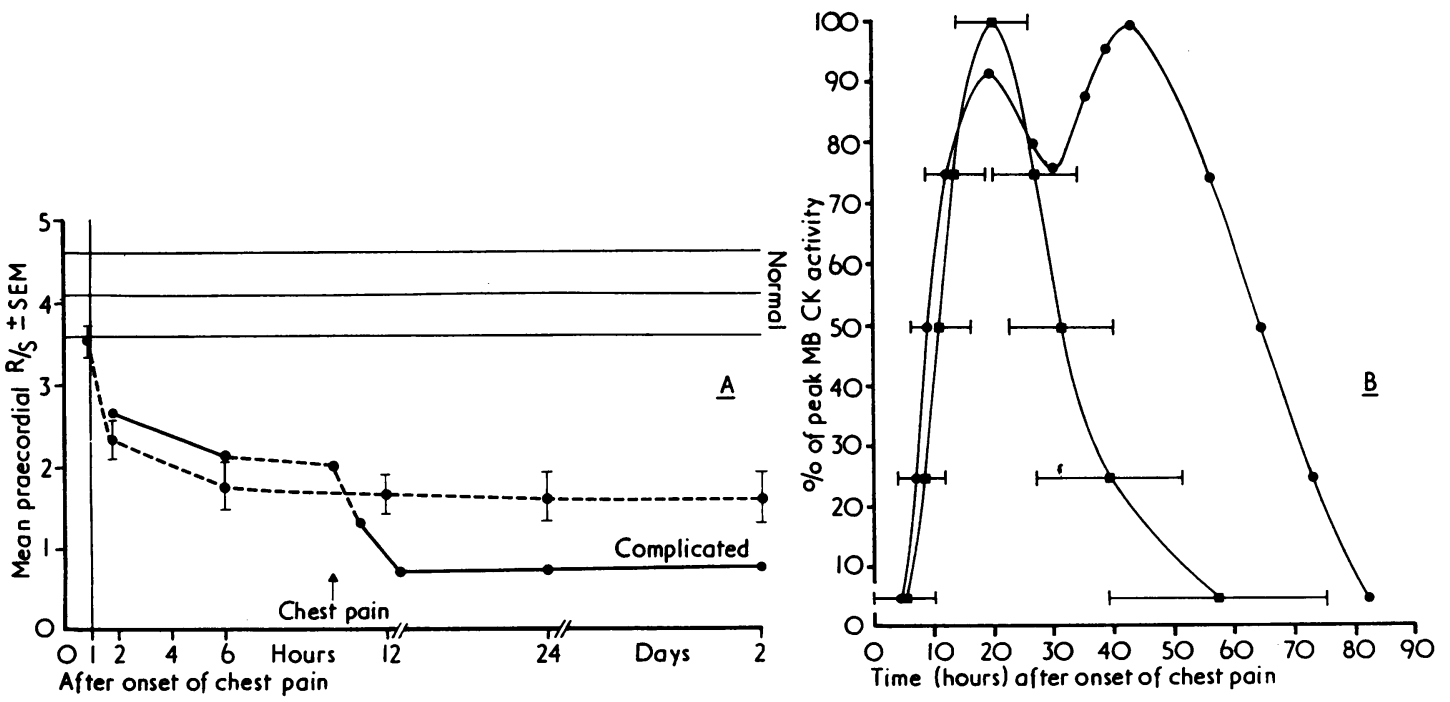

Fig. 4 (A) The changes seen in the mean $\pm S E M$ of the praecordial $R / S$ ratios in 40 patients with uncomplicated anterior infarction are shown. The changes in the mean $R / S$ ratio in a patient with recurrent chest pain 12 hours after the initial episode shows further reduction in $R / S$ ratio. (B) Serial plasma $M B C K$ activity (expressed as a percentage of the peak value) in patients with uncomplicated infarction and in the patient illustrated in $(A)$ with recurrent chest pain. The time taken for the plasma $M B C K$ activity to reach 5, 25, 50, 75, and 100 per cent of the peak value is plotted for the release and clearance phases of the curves; the mean $\pm 2 S D$ is shown for the uncomplicated group. 


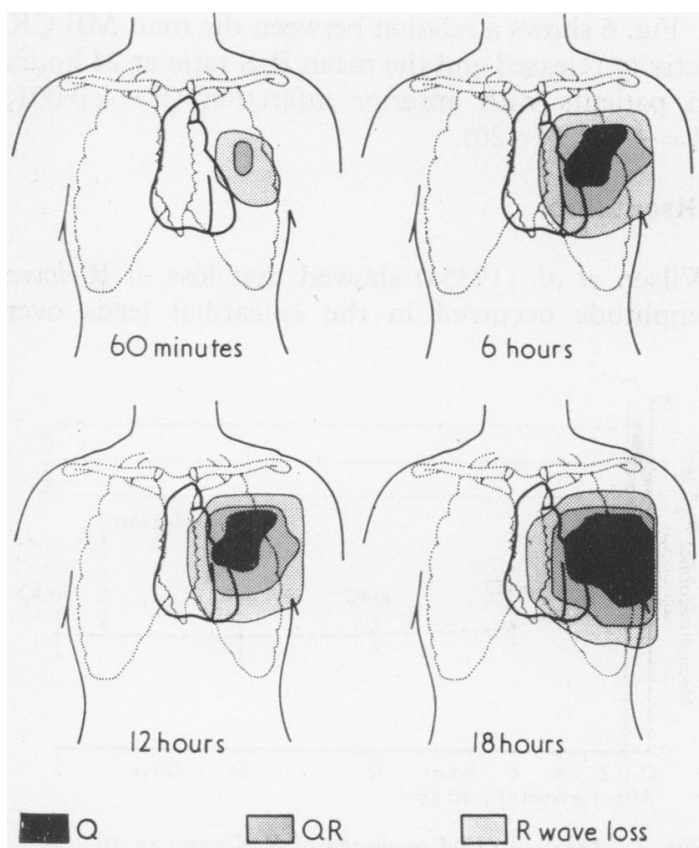

Fig. 5 Serial praecordial surface maps in the same patient with anterior infarction who had recurrent chest pain at 12 hours. These show a significant extension of the areas in which loss of $R$ waves and development of $Q$ waves are seen. This did not occur in the uncomplicated group (Fig. 2) and is associated with the abnormal $M B$ CK release curve (Fig. $4 B$ ).

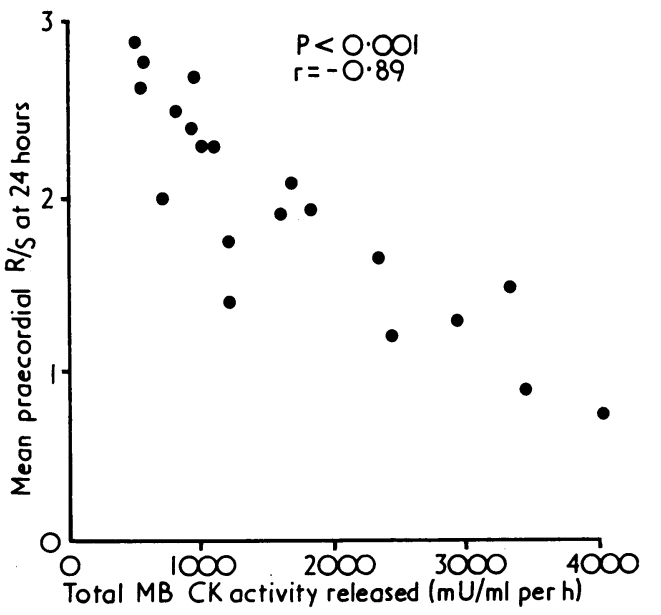

Fig. 6 The relation between the reduction in $R / S$ ratio on the praecordial map seen at 24 hours and the total release of $M B C K$ activity in the plasma in patients with anterior infarction was significant. ischaemic myocardium and concluded that this was the result of the absence of electrical forces normally produced by the portion of ventricular wall deprived of its blood supply. Studies have shown that a reduction of $R$ wave voltage is found at sites in which ischaemia produced a mixture of viable and necrotic myocardium (Prinzmetal et al., 1954; Shaw et al., 1954). In this study a range of values of $R / S$ ratio and $R$ waves for the 72 point praecordial map has been determined for a group of people with no detectable cardiovascular disease. These findings in normal subjects at rest and in the same position did not vary more than \pm 4 per cent when maps were repeated over many days, and $\mathrm{Qr}$ and $\mathrm{Q}$ waves were not seen in this normal group. In contrast to this, the group with anterior infarction showed serially, changing abnormal areas of $R / S$ ratio, and $Q r$ and $Q$ waves which can be outlined on surface maps.

In a group of patients with uncomplicated anterior infarction, serial mapping of the praecordial electrocardiogram showed an initial increase in $R$ wave amplitude in 3 patients mapped within 20 minutes from the onset of chest pain (Fig. 3). Significant loss of $\mathbf{R}$ wave was detectable at 30 minutes and was complete within 6 hours of the onset of chest pain. After 12 hours from the onset of chest pain changes in $R / S$ ratio, and fresh appearance of $Q$ waves could not be detected with this technique.

ST segment elevation in acute regional myocardial ischaemia has been widely studied (Samson and Scher, 1960; Maroko et al., 1971; Muller et al., 1975); however, in experimental work it does not provide direct information about the death of myocardium, and in clinical practice it cannot be used to assess the progressive loss of active myocardium in acute infarction (Reese et al., 1973; Norris et al., 1976; Selwyn et al., 1977).

The location and distribution of the praecordial electrocardiographic changes depend on the site of the ischaemic area and the position of the heart in relation to the 72 points on the chest, and on the distance between the electrodes and the heart and the resistance of the tissues between. The borders of the electrocardiographic manifestations of ischaemia will be influenced by the intervening normal tissue. Accepting these reservations, experimental research has shown a close correlation between the epicardial and praecordial electrocardiographic $R$ wave and ST segment changes during ischaemia (Muller et al., 1975).

In conclusion, this study has shown that praecordial mapping of the electrocardiogram provides a repeatable and noninvasive assessment of the progressive loss of electrically active myocardium 
in patients with anterior infarction. $\mathrm{MB} \mathrm{CK}$ is essentially cardiospecific and the total amount of various enzymes released into the plasma provides a quantitative assessment of the extent of muscle necrosis in acute myocardial infarction (Sobel et al., 1972; Mathey et al., 1974). We have shown that the loss of $R$ wave voltage and development of $Q$ waves were complete by 24 hours and that the extent of these changes correlated with the total MB CK activity released into the plasma.

Serial observations on the loss of $\mathbf{R}$ waves and appearance of $Q$ waves in 40 patients with uncomplicated anterior infarction suggest that in this group the loss of electrically active myocardium occurs within 6 hours from the onset of chest pain. The technique makes it possible to assess complications that may be associated with extension of the loss of active myocardium, and may prove useful in identifying those factors that modify the progress of cell death and loss of viable tissue in the early phase of acute infarction and thus in limiting infarct size.

The authors wish to thank Miss Aviva Petrie and Dr. John Osborne, consultant statisticians, for advice.

\section{References}

Blackburn, H., Keys, A., Simonson, E., Rautaharju, P., and Punsar, S. (1960). The electrocardiogram in population studies. Circulation, 21, 1160-1175.

Craig, F. A., Smith, J. C., and Foldes, F. F. (1967). Effect of dilution on the activity of serum creatine phosphokinase. Clinica Chimica Acta, 15, 107-111.

Hearse, D. J., Humphrey, S. M., and Chain, E. B. (1973). Abrupt reoxygenation of the anoxic potassium-arrested perfused rat heart: a study of myocardial enzyme release. Fournal of Molecular and Cellular Cardiology, 5, 395-407.

Johnston, F. D., Hill, I. G. W., and Wilson, F. N. (1935). The form of the electrocardiogram in experimental myocardial infarction. II. The early effects produced by ligation of the anterior descending branch of the left coronary artery. American Heart fournal, 10, 889-902.

Maroko, P. R. (1974). Assessing myocardial damage in acute infarcts. Editorial. New England Fournal of Medicine, 290, 158-159.

Maroko, P. R., Kjekshus, J. K., Sobel, B. E., Watanabe, T., Covell, J. W., Ross, J., and Braunwald, E. (1971). Factors influencing infarct size following experimental coronary artery occlusions. Circulation, 43, 67-82.

Mathey, D., Bleifeld, W., Hanrath, W., and Effert, S. (1974). Attempt to quantitate relation between cardiac function and infarct size in acute myocardial infarction. British Heart fournal, 36, 271-279.

Muller, J. E., Maroko, P. R., and Braunwald, E. (1975).
Evaluation of precordial electrocardiographic mapping as a means of assessing changes in myocardial ischemic injury. Circulation, 52, 16-27.

Norris, R. M., Barratt-Boyes, C., Heng, M. K., and Singh, B. N. (1976). Failure of ST segment elevation to predict severity of acute myocardial infarction. British Heart fournal, 38, 85-92.

Ogunro, E. A., Hearse, D. J., and Shillingford, J. P. (1977). Creatine kinase isoenzymes: their separation and quantitation. Cardiovascular Research, 11, 94-102.

Oliver, I. T. (1955). A spectrophotometric method for the determination of creatine phosphokinase and myokinase. Biochemical fournal, 61, 116-122.

Prinzmetal, M., Shaw, C. McK., Maxwell, M. H., Flamm, E. J., Goldman, A., Kimura, N., Rakita, L., Borduas, J-L., Rothman, S., and Kennamer, R. (1954). Studies on the mechanisms of ventricular activity IV. American fournal of Medicine, 16, 469-489.

Reese, L., Scheidt, S., and Killip, T. (1973). Variability of precordial ST segment maps after acute myocardial infarction in man (abstract). Circulation, 47-48, Suppl. IV, 38.

Reid, D. S., Pelides, L. J., and Shillingford, J. P. (1971). Surface mapping of the RS-T segment in acute myocardial infarction. British Heart fournal, 33, 370-374.

Rose, G. A., and Blackburn, H. (1968). Cardiovascular survey methods. World Health Organization. Monograph Series, No. 56. Geneva.

Samson, W. E., and Scher, A. M. (1960). Mechanism of S-T segment alteration during acute myocardial injury. Circulation Research, 8, 780-787.

Selwyn, A. P., Ogunro, E., and Shillingford, J. P. (1977). Natural history and evaluation of ST segment changes and MB CK release in acute myocardial infarction. British Heart fournal, 39, 988-994.

Selwyn, A. P., and Shillingford, J. P. (1977). Praecordial mapping of $Q$ waves and $R S$ ratio changes in acute myocardial infarction. Cardiovascular Research, 11, 167-171.

Shaw, C. McK., Goldman, A., Kennamer, R., Kimura, N., Lindgren, I., Maxwell, M. H., and Prinzmetal, M. (1954). Studies on the mechanism of ventricular activity. VIII. The origin of the coronary $\mathrm{QR}$ wave. American Fournal of Medicine, 16, 490-503.

Sobel, B. E., Bresnahan, G. F., Shell, W. E., and Yoder, R. D. (1972). Estimation of infarct size in man and its relation to prognosis. Circulation, 46, 640-648.

Wilson, F. N., Hill, I. G. W., and Johnson, F. D. (1935a). The form of the electrocardiogram in experimental myocardial infarction. III. The later effects produced by ligation of the anterior descending branch of the left coronary artery. American Heart fournal, 10, 903-915.

Wilson, F. N., Johnston, F. D., and Hill, I. G. W. (1935b). The form of the electrocardiogram in experimental myocardial infarction. IV. Additional observations on the later effects produced by ligation of the anterior descending branch of the left coronary artery. American Heart fournal, 10, 1025-1041.

Requests for reprints to Dr. A. P. Selwyn, Cardiovascular Research Unit, Royal Postgraduate Medical School, Hammersmith Hospital, Du Cane Road, London W12 0HS. 